Technological University Dublin

DÜBLIN

ARROW@TU Dublin

Articles

DIT Biophotonics and Imaging

2020-2

\title{
Can Ethanol Affect the Cell Structure - a Dynamic Molecular and Raman Spectroscopy Study
}

Luis Felipe Carvalho

Universidade do Vale do Paraiba, Brazil

LAURITA DOS SANTOS

UNIVERSIDADE DO VALE DO PARAÍBA, SÃO JOSÉ DOS CAMPOS

Kate O'Callaghan

Trinity College Dublin, Ireland

See next page for additional authors

Follow this and additional works at: https://arrow.tudublin.ie/biophonart

Part of the Physics Commons

\section{Recommended Citation}

Carvalho, L.P. et al (2020) Can ethanol affect the cell structure - a dynamic molecular and Raman spectroscopy study, Photodiagnosis and Photodynamic Therapy, 30, 101675 (2020) doi:10.1016/ j.pdpdt.2020.101675.

This Article is brought to you for free and open access by the DIT Biophotonics and Imaging at ARROW@TU Dublin. It has been accepted for inclusion in Articles by an authorized administrator of ARROW@TU Dublin. For more information, please contact arrow.admin@tudublin.ie, aisling.coyne@tudublin.ie,gerard.connolly@tudublin.ie.

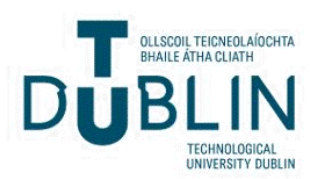




\section{Authors}

Luis Felipe Carvalho, LAURITA DOS SANTOS, Kate O'Callaghan, Franck Bonnier, Steven Flint, Fiona Lyng, and Hugh Byrne

This article is available at ARROW@TU Dublin: https://arrow.tudublin.ie/biophonart/53 


\section{Can ethanol affect the cell structure - a dynamic molecular and Raman spectroscopy study}

Running title: Analysis of ethanol exposure in oral cell lines

Luis Felipe CS Carvalho ${ }^{1,7,8^{*}}$, Laurita dos Santos ${ }^{5}$, Franck Bonnier ${ }^{6}$, Kate $O^{\prime}$ Callaghan $^{2}$, Jeff O'Sullivan ${ }^{2}$, Stephen Flint ${ }^{2}$, Lázaro PM Neto ${ }^{5}$, Airton A Martin ${ }^{5}$, Fiona M. Lyng ${ }^{3,4}$ and Hugh J. Byrne ${ }^{1,}$

${ }^{1}$ FOCAS Research Institute, Technological University Dublin, Kevin Street, Dublin 8

${ }^{2}$ Dublin Dental School and Hospital, Trinity College Dublin, Dublin 2

${ }^{3}$ Radiation and Environmental Science Centre, FOCAS Research Institute, Technological University Dublin, Kevin Street, Dublin 8

${ }^{4}$ School of Physics, Technological University Dublin, Kevin Street, Dublin 8 Ireland

${ }^{5}$ Laboratory of Biomedical Vibrational Spectroscopy, Universidade do Vale do Paraíba, São José dos Campos-SP Brazil

${ }^{6}$ Université François-Rabelais de Tours, Faculty of Pharmacy, EA 6295

Nanomédicaments et Nanosondes, 31 avenue Monge, 37200 Tours, France.

7 Universidade de Taubate, Tauabté-Brazil

8 Centro Universitário Braz Cubas, Mogi das Cruzes-SP

Email of corresponding author: luisfelipecarvalho@hotmail.com

FAPESP (2014/05978-1)

CNPq $(237749 / 2012-2)$

CAPES (88881.062862/2014-01). 


\begin{abstract}
The role that tobacco consumption plays in the etiology of oral cancer carcinogenesis, and of alcohol consumption acting as a co-factor, have been well established. However, in recent years, the contribution of alcohol consumption alone to oral cancer has been proposed. In fact, a high percentage of patients who develop oral cancer have both habits (tobacco and alcohol consumption), and other small patient groups only consume alcohol or do not have any other identifiable bad habits. In the present study, we demonstrate for the first time, using a combination of dynamic molecular modelling and Raman spectroscopy, that ethanol has a significant effect on oral cells in vitro, mainly interacting with the lipids of the cell membrane, changing their conformation. Thus, it is possible to conclude that ethanol can affect the cell permeability, and by consequence serve as a possible trigger in oral carcinogenesis.
\end{abstract}

Key-words: oral cancer, carcinogenesis, dynamic molecular modelling, ethanol, Raman spectroscopy, lipids 


\section{INTRODUCTION}

Oral cancer is one of the more common cancers worldwide and, in less-developed countries, is next in prevalence to skin and breast cancer [1]. Tumors are primarily located around the tongue, floor of the mouth, gingiva and buccal mucosa $[2,3]$.

Alcohol consumption and cigarette smoking are established risk factors for head and neck cancer (HNC) originating from the oral cavity, pharynx, and larynx, and are likely to be differentially associated with risk of those head and neck cancer-subtypes[4]. A greater than multiplicative, synergistic effect between alcohol and tobacco consumption has been shown, but most evidence comes from case-control studies [4-11]. Ethanol is a small amphiphilic molecule (with polar and apolar regions) that may interact with water and lipids. This molecule has been shown to effect biological systems such as yeast and bacterial cells [12], and can induce cell membrane remodeling [13]. Maasland et al.[4] investigated whether alcohol consumption and cigarette smoking are strongly, positively associated with HNC-risk, with synergistic interactions, and whether these risks are different for oral cavity cancer (OCC), oro-/hypopharyngeal cancer (OHPC), and laryngeal cancer (LC). A significant, positive, synergistic interaction between categories of alcohol consumption and cigarette smoking was found for HNC overall.

In order to further understand the alterations induced by ethanol on the cell membrane and subsequently on the whole cell, dynamic molecular modelling can be utilized to mimic the interaction between the cell membrane and ethanol molecules. For example, in a similar fashion, Posokhov et al, [14] described the interaction with POPC (1-Palmitoyl2-oleoylphosphatidylcholine) bilayer and acetone molecules and facilitated detection of a perturbation of bilayer structure. This mechanism is similar to that of other amphiphilic molecules, such as alcohols. Extrapolating the membrane perturbation effect, the 
accumulation of these molecules leads to penetration of the cell, causing morphological and biochemical alterations [13-15].

To support the results of the molecular modeling, Raman spectroscopy can be employed to verify changes in the molecular composition of the cell membrane. Raman spectroscopy is a label-free technique that can be used to follow, in real time, the changes induced by risk factors associated with carcinogenesis. The technique is of special interest due to its high sensitivity in the detection of biochemical and molecular variations in tissues $[16,17]$. Indeed, such optically-based spectroscopic techniques are prominent among potential candidate non-invasive and rapid diagnostic methods. These methods are widely used as a tool for analysis of many biological tissues and the techniques have been referred to as an "optical biopsy"[18-21] or "spectral histo/cytopathology"[22] because of their capacity to show features of underlying pathological tissues/cells when compared with normal samples. Although clinical diagnosis of late stage, invasive oral cancer is relatively straightforward, the clinical challenge remains to detect early cancerous lesions, which are significantly harder to identify. Surgical treatment of early oral squamous cell carcinoma involves much less extensive and complex surgery and leads to a significant reduction in co-morbidity and increase in quality of life [23]. Raman spectroscopy is one of the most popular emerging spectroscopic techniques and has demonstrated potential in studies examining different types of cancer, including lung cancer [24], neural cancer [25], breast cancer [26,27] cervical cancer [28], gastric cancer [29], skin cancer [30] and head and neck cancer [31].

Usually, the spectral region between $\sim 500$ and $1,800 \mathrm{~cm}^{-1}$ (fingerprint region) is viewed as the most relevant biochemical information concerning biological tissues $[16,17,32]$. Many vibrational band frequencies of amino acids, nucleic acids, proteins, lipids, glucose, and other carbohydrates fall in this region[16-33]. An alternative is to analyze the bands 
in the high wavenumber $(\mathrm{HWN})$ region $\left(2,800-3,600 \mathrm{~cm}^{-1}\right)$, related to $\mathrm{OH}, \mathrm{CH}, \mathrm{CH}_{2}$, $\mathrm{CH}_{3}$, and $\mathrm{NH}$ stretch vibrations, more specifically due to lipids, proteins, carbohydrates, among other species present. Nazemi and Brennan [34] evaluated lipid concentrations in the human coronary artery by high wavenumber Raman spectroscopy. The reported results showed accurate compositional information of the human coronary artery and raised the possibility of determining this information in vivo via small-profile cardiovascular catheters. Vyumvuhore et al.[35] studied the effects of atmospheric relative humidity on the stratum corneum structure at the molecular level using high wavenumber Raman spectroscopy, elucidating the specific interactions of water with the lipidic structures. These studies demonstrate the potential of Raman spectroscopy, specifically in the HWN region, to monitor changes in lipidic structures and interactions with cell membranes.

The main purpose of the present work is therefore to assess biochemical changes in oral mucosa cells after exposure to ethanol $(1 \% \mathrm{v} / \mathrm{v})$, specifically in the cell membrane. The techniques employed are simulations of the interactions using dynamic molecular modelling to elucidate the mechanisms and extent of interaction of ethanol with the cell membranes and Raman spectroscopy as a complementary spectroscopic technique to verify the predicted biochemical changes in the cells, specifically in the HWN region, which is more sensitive to lipidic structures. The fingerprint region of the Raman spectrum contains complex contributions from all biochemical constituents within the measurement voxel (spot size $\sim 1 \mathrm{~mm}$ ), potentially including membrane lipids and proteins and other constituents of the cytosol and cytoskeleton. In contrast, the high wavenumber $(\mathrm{HWN})$ region contains signatures of the normal modes of $\mathrm{CH}, \mathrm{OH}, \mathrm{NH}$ vibrations, and is thus less convoluted. In particular, the $\mathrm{CH}_{2}$ backbone of lipids is a dominant contributor 
in this region, and thus the Raman analysis to verify the molecular simulation of changes to the membrane lipid structure as a result of ethanol was concentrated in this region.

A selection of cell lines representative of varying pathologies; SCC4 (malignant cell line) and Ca9.22 (malignant cell line), DOK (dysplastic cell line) and primary cells (normal oral epithelial cells), were treated with $1 \%$ ethanol. The level of ethanol exposure was chosen such that it would have limited effect on cellular metabolic function and viability (in the short term) but would still illicit a response [36]. Although the objective of the work was primarily to explore the effect of ethanol exposure on normal cells, the range of different cell lines were employed to demonstrate that the ethanol exposure can affect cells of different representative pathologies.

\section{MATERIALS AND METHODS}

\section{MOLECULAR DYNAMICS SIMULATION}

The simulation was executed with Gromacs 4.5.5 package [37] using the united-atom force field model of [38] (considering ethanol and DPPC molecules), applying periodic boundary conditions in all dimensions ( $\mathrm{x}, \mathrm{y}$ and $\mathrm{z}$ ). The cut-offs of the electrostatic and van der Waals interactions were adjusted to $1.2 \mathrm{~nm}$. The Berendsen barostat [39] is used for pressure coupling and V-rescale thermostat [40] was used for temperature control.

The simulated model elaborated contained 128 DPPC phospholipid molecules aligned as a bilayer with the hydrophobic part (tail groups) inside the model and the hydrophilic part (head groups) outside the model, interacting with 3643 water molecules and 12 ethanol molecules ( $1 \%$ concentration). The size of the box simulation obtained was $6.2 \mathrm{~nm}$ (x axis) x $6.2 \mathrm{~nm}$ (y axis) x $6.7 \mathrm{~nm}$ (z axis). 
To assess the possible alterations in the bilayer before and after interaction with $1 \%$ of ethanol in water, the distance between two phosphorus (P) atoms of the head-group of DPPC in each monolayer was calculated using the GridMat-MD version 2.0 [41].

\section{ORAL CELL LINES}

To determine the efficacy of Raman Spectroscopy in distinguishing between the four different cell lines treated and untreated with $1 \%$ ethanol. The level of ethanol exposure was chosen such that it would have limited effect on cellular metabolic function and viability (in the short term) but would still illicit a response to the exposure [36]. Four different types of oral cell lines: Ca9.22 (malignant cell line), TR (malignant cell line), DOK (dysplastic cell line) and Primary cells (normal oral epithelial cells) were utilized.

DOK/ Ca9.22 cell cultures:

The /DOK/Ca9.22 (HPA cultures, UK) cell lines were cultured in Dulbecco Modified Eagle's Medium (DMEM) supplemented with 10\% (v/v) FBS, penicillin/streptomycin (100U/100ug) and L-glutamine $(2 \mathrm{mM})$. For the DOK cell line, hydrocortisone $(5 \mathrm{ug} / \mathrm{ml})$ was also added. The medium was pre-warmed at $37^{\circ} \mathrm{C}$ before incubation of the cells. Cells were cultured until 90\% confluency in a humidified environment at 5\% CO2, before being passaged. When confluent, the cells were washed in pre-warmed phosphate buffered saline (PBS) (0.01M phosphate buffer, $0.154 \mathrm{M}$ sodium chloride) and incubated with trypsin-EDTA $(0.5 \%$ trypsin, $0.02 \%$ EDTA $)$ for 5 min at $37^{\circ} \mathrm{C}$. Fresh, pre-warmed medium was added to deactivate trypsin, and the suspended cells were centrifuged at $250 \mathrm{~g}$ for $5 \mathrm{~min}$. The supernatant was discarded and the cell pellet was resuspended in a sufficient volume of fresh pre-warmed medium, counted and passaged at a suitable density for each individual cell line. 
Human oral mucosa was recovered at the Dublin Dental University Hospital from patients undergoing routine third molar extraction in the Department of Oral and Maxillofacial Surgery. The tissue was immediately placed into pre-warmed collection medium [DMEM, penicillin/streptomycin $(100 \mathrm{U} / 100 \mu \mathrm{g})$, amphotericin B $(2.5 \mu \mathrm{g} / \mathrm{ml})$ ] for $10 \mathrm{~min}$ before washing the tissue three times with pre-warmed $1 \mathrm{X}$ PBS and placing it in $0.17 \%$ trypsin overnight at $4^{\circ} \mathrm{C}$. The following day, the sample was washed with $1 \mathrm{X}$ PBS and connective tissue was removed using a scalpel. The tissue was cut into small pieces $(1 \mathrm{~mm}$ $\mathrm{x} 2 \mathrm{~mm}$ ) and the small sections were placed in pre-treated T25 flasks (CELL+, Sarstedt), each with a small coating of keratinocyte growth medium (KGM). These were left to adhere to the flask for $1-2 \mathrm{~h}$ and the flask was subsequently gently flooded with KGM. Once sufficient growth of cells from tissue was achieved (2-3 weeks), KGM was replaced with Epilife medium (Invitrogen) to select for epithelial cell growth. Cells were passaged using $0.05 \%$ trypsin and spun at $250 \mathrm{~g}$ for $10 \mathrm{~min}$ at $4{ }^{\circ} \mathrm{C}$ and cultured to $90 \%$ confluency.

\section{SAMPLE PREPARATION}

To facilitate Raman spectroscopy measurements, cells were detached from the flasks using $0.025 \%$ Trypsin-EDTA at $37^{\circ} \mathrm{C}$ and pelleted at $250 \mathrm{~g}$ for $5 \mathrm{~min}$ at room temperature. The supernatant was removed and cells were counted and seeded at a density of 5 x 104 cells/calcium fluoride $\left(\mathrm{CaF}_{2}\right)$ disc in a multiwell plate and maintained, as previously described, until a monolayer of cells was stably growing on the disc. The cells were then fixed with 10\% neutral buffered formaldehyde for $5 \mathrm{~min}$, washed with $1 \mathrm{X}$ PBS and stored in $0.9 \%$ physiological saline solution prior to capture of the Raman spectrum.

\section{RAMAN SPECTROSCOPY MEASUREMENTS}

The study was conducted with a Horiba Jobin-Yvon LabRam HR800 instrument using a $532 \mathrm{~nm}$ laser as the source in a backscattering geometry, and a 300 lines/mm grating, 
providing a dispersion of $\sim 1.5 \mathrm{~cm}^{-1}$ per pixel. The laser power was approximately $35 \mathrm{~mW}$ at the sample. Spectra were taken in the range from $2800 \mathrm{~cm}^{-1}$ to $3600 \mathrm{~cm}^{-1}$ with a confocal hole diameter of $100 \mu \mathrm{m}$. A 100x water immersion objective (LUMPlanF1, Olympus, N.A.: 1.0) was used to focus the laser on the sample, immersed in distilled water, providing a spatial resolution of $\sim 1 \mu \mathrm{m}$ [42]. Measurement in water immersion has been demonstrated to reduce any photothermal damage to the cells during measurement, and the high signal to noise spectroscopic signals were observed to be stable and reproducible over prolonged illumination [43]. In total 80 cells were analyzed in the ethanol treated group and 80 cells without treatment. For each cell, the cytoplasmic region was analyzed, resulting in one spectrum for each subcellular region of each cell. Thus, for each cell line, 20 cells were analyzed, resulting in 20 spectra per cell line each for a period of $2 \times 20$ seconds (Figure1).

\section{DATA PREPROCESSING}

Data preprocessing was performed using Matlab (Mathworks, USA). Before statistical analysis, a Savitsky-Golay filter (5th order, 7 points) was applied to smooth the spectra. All spectra were (vector) normalized to remove point to point intensity variations and facilitate comparison of all spectra.

\section{DATAANALYSIS}

An average of all spectra of control and ethanol exposed cells enabled identification of potentially differentiating spectral features. Subsequently, the spectra of the cytoplasm of control and exposed normal (80 spectra - primary), precancerous (20 spectra - DOK), and cancerous (40spectra -Ca9.22 and TR) cells were compared. Unpaired Student's t-test or Mann-Whitney test (if the data is not a Gaussian distribution) of the intensity peaks 
related to lipid vibrations $\left(2851 \mathrm{~cm}^{-1}\right)$ and the integrated area of $2817-3000 \mathrm{~cm}^{-1}$ were used as a discrimination method.

\section{RESULTS:}

\section{SIMULATION ANALYSIS}

To visualize the interactions of the ethanol at a cellular level, a series of models simulating the molecular interactions of the ethanol with the lipid bilayer of the cell membrane were developed. The lipid bilayer model selected for use with Molecular Dynamics (MD) is based on dipalmitoylphosphatidylcholine (DPPC) phospholipid [44], which is the most common representation for biological membranes. This DPPC bilayer model is distributed by Peter Tieleman (http://wcm.ucalgary.ca/tieleman/downloads).

Figure 1 shows the system at the beginning (1a) and end (1b) of the simulation. The yellow spheres in Figure 1a represent the ethanol molecules, and they are initially randomly spread in the simulated water matrix (red) surrounding the phospholipids (blue). The system has been equilibrated, in terms of potential energy, i.e., the energy was minimized. After $100 \mathrm{~ns}$, the interaction between the molecules within the system leads to the penetration of ethanol molecules into the lipid bilayer and a subsequent disruption of the ordered structure of those layers (Figure 1b).

The density profile (Figure 1c) represents the relative position of the ethanol molecules with respect to the lipid bilayer model over the duration of the simulation, at 0 ns and 100 ns. In order to obtain the relative position profile, the center of mass and the number of molecules are considered. Note that the phospholipid layers increase in relative thickness, retaining the bilayer structure in the box simulation, reflected in terms of a comparison between Figure 1a and 1b. The simulated system is dynamic and movement among the molecules due to interactions is expected. 


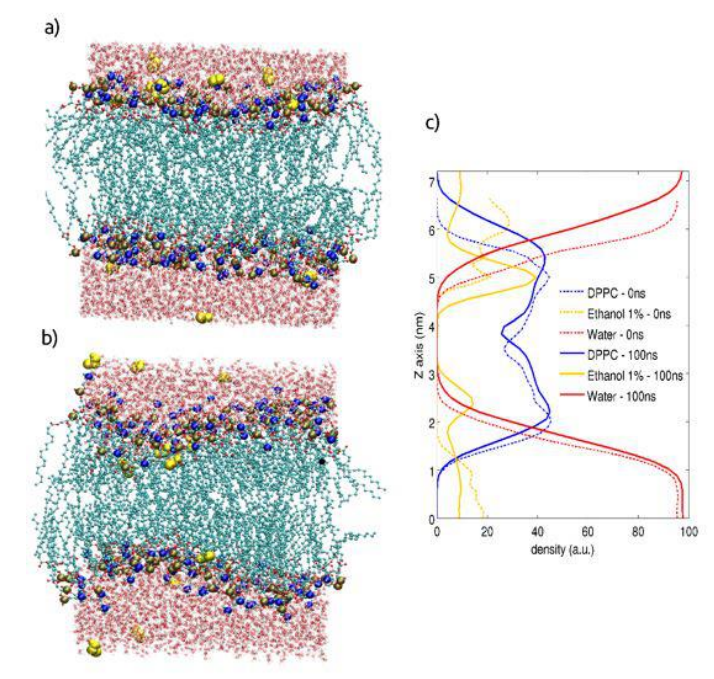

Figure 1: Image displaying the interaction between the cell membrane and $1 \%$ ethanol prepared using molecular dynamics: a) 0 ns of simulation and b) after end of simulation (100ns). c) Density profile (arbitrary units) of the molecules in the system at initiation (dash line) and termination (solid line) of the simulation.

However, the ethanol profile indicates that, although in the first image only some molecules interact with the lipid groups, after 100ns, some have penetrated into the bilayer. The amphiphilic nature of the ethanol and its ability to establish hydrogen bonds with -OH may attract the water molecules to the inside of phospholipid bilayer. The attraction of water by ethanol molecules results in a disruption of the bilayer and alters its thickness.

It is noted that these interactions among ethanol-water and DPPC lead to the perturbation of the bilayer structure. This perturbation is primarily related to thickness modification of the bilayer (Figure 2 and Figure 3). 


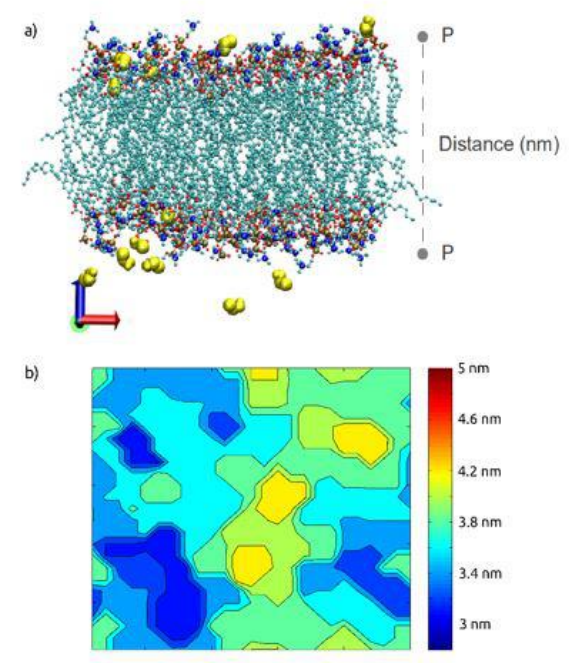

Figure 2: Image capture of the initiation of the simulation at $0 \mathrm{~ns}$ (a) and its matrix thickness (b). The matrix is calculated based on the distance between two phosphorus (P) atoms of the two DPPC molecules aligned in different monolayers.

To represent the bilayer thickness, the distance $(\mathrm{nm})$ between two phosphorus $(\mathrm{P})$ atoms of two DPPC molecules aligned in different phospholipid monolayers is calculated. Figure 2 shows an image of the system at the initial stage of evolution $(t=0)$ and Figure 3 shows the final stage $(\mathrm{t}=100 \mathrm{nsec})$. The matrix distances obtained are shown in Figure $2 \mathrm{~b}$ and Figure 3b, wherein the smallest distance $(2.8 \mathrm{~nm})$ is represented by a blue color and the largest distance found is represented by red. It is noted that, in Figure 3a, the highlighted section displays the region of bilayer that has the highest perturbation, considering the alignment of lipids. 


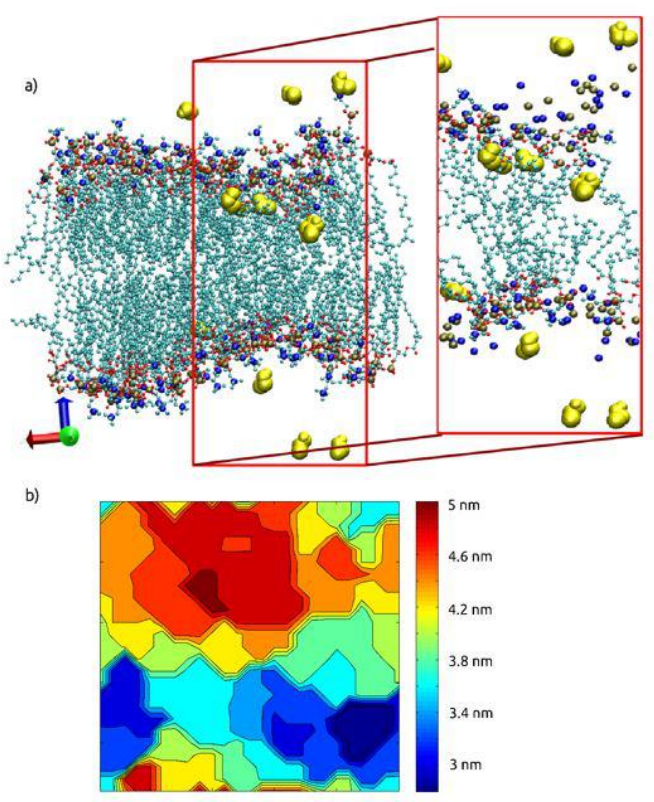

Figure 3: Image capture of the termination of the simulation at $100 \mathrm{~ns}$ and its matrix thickness. In this distance matrix the red color (largest distance between two P atoms) is predominant compared with Figure 2.

\section{RAMAN ANALYSIS}

Molecular simulations predict a strong interaction of ethanol with the lipid membrane of the cell, resulting in a significant disruption of its structure. Such effects should be manifest in the Raman spectrum of the cell membrane, particularly in the high wavenumber region $\left(2800-3600 \mathrm{~cm}^{-1}\right)$, which is dominated by vibrational modes of $\mathrm{CH}_{2}$, $\mathrm{CH}_{3}, \mathrm{NH}$ and $\mathrm{OH}^{45}$. Figure 4 shows the average spectra of all cell lines as unexposed control (in black), together with the average spectrum of all cell lines treated with ethanol (in red). Broad $\mathrm{OH}$ vibrations from water, at $\sim 3100-3500 \mathrm{~cm}^{-1}$, are very prominent, but in the present analysis their contribution is not significant, firstly because we are interested in alterations of the biological components, and secondly, because the vibrational modes of water come mainly from the immersion environment and not from the sample itself. 
In the region indicated in Figure 4, vibrational bands associated with $\mathrm{CH}_{2}$ and $\mathrm{CH}_{3}$ groups of lipids and proteins are clearly visible. Notably, significant differences are evident in the $\mathrm{CH}_{2} / \mathrm{CH}_{3} \mathrm{HWN}$ vibrational modes of the Raman spectra of control cells and cells exposed to ethanol (Figure 4), which are mainly related to the lipid and/or membrane phospholipid conformation, especially the band at $2851 \mathrm{~cm}^{-1}$, which is indicative of the $\mathrm{CH}_{3} /$ lipid vibrations [16].

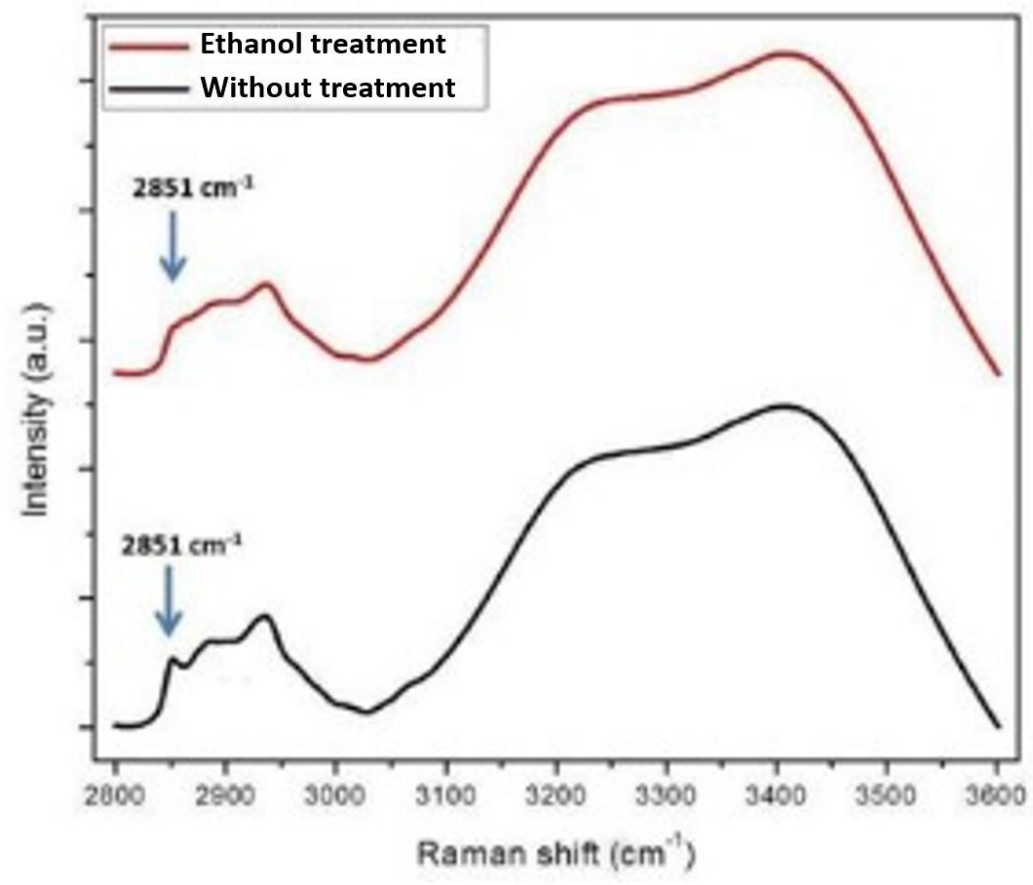

Figure 4: Averaged high wavenumber Raman spectra of all cell lines before (red) and after (black) $1 \%$ ethanol treatment. MannWhitney test of the lipid vibrational modes shows that changes in the region are statistically significant, $\mathrm{p}<0.001$, demonstrating excellent discrimination of these types of samples in the region related to the vibrational modes of lipids $/ \mathrm{CH}_{3}$.

A Mann-Whitney test of the lipid vibrational modes shows that the feature at $2851 \mathrm{~cm}^{-1}$ is statistically significant, $\mathrm{p}<0,0001$, demonstrating the excellent discrimination of these types of samples in the region related to the vibrational modes of lipids $/ \mathrm{CH}_{3}$.

To demonstrate that the observed effect is observable in cells representative of different pathologies, the effects of the ethanol exposure on each individual cell line was examined. 
Figure 5 demonstrates that the ethanol exposure strongly affects each of the cell lines, as manifest in the change in the intensity of the Raman feature at $2851 \mathrm{~cm}^{-1}$, with statistically significant results in normal and pre cancer cells.
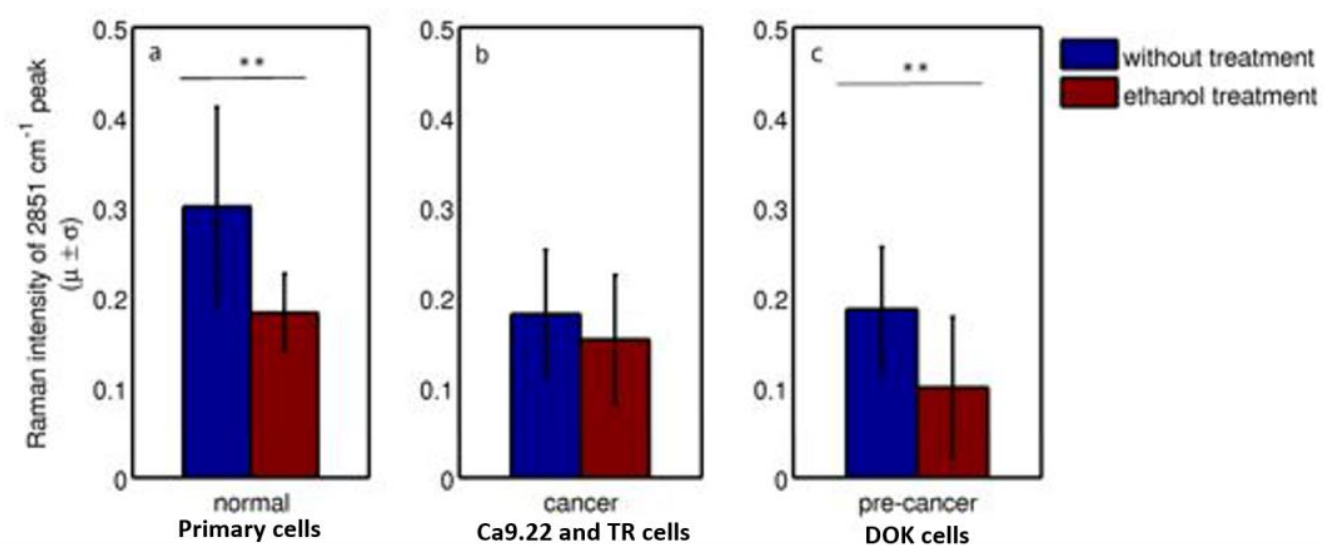

Figure 5: Relationship between the intensity of the $2851 \mathrm{~cm}^{-1}$ peak for each cell line in the presence and absence of ethanol, ** p $<$ 0.001 and $* \mathrm{p}<0.05$.

\section{DISCUSSION}

Many authors believe that ethanol exposure, in the absence of smoking, cannot lead to a carcinogenic process, but that it rather acts as an adjuvant "helping" the carcinogenic tobacco effect, although it is not understood how the ethanol could act in the tissue [210]. Some researchers suggested that the ethanol could interfere at the membrane junction areas at the spinal and granular layer, facilitating the action of tobacco at the basal layer, and initiating the epidermoid carcinoma process [2-10].

In this study, dynamic molecular modelling simulations provide evidence for a significant direct effect of ethanol exposure (1\%) with the lipidic structures of the cell membranes. The well-structured lipid bilayer before exposure $(t=0)$, is significantly perturbed by the ethanol exposure, resulting in changes in membrane structure and thickness, and by 
$\mathrm{t}=100 \mathrm{nsec}$, ethanol molecules can be seen to penetrate the membrane, compromising its barrier function.

Raman spectroscopy, through the analyses of the effect of ethanol exposure on the cell cytoplasm, confirms that the lipid content is strongly affected, and correlates to the dynamic molecular simulation demonstrating the potential effect on the plasma membrane structure. When compared to the control cells, the ethanol treated cell cultures showed significant variation in their spectra. Interestingly, the discrimination was observed in the $\mathrm{CH}_{3}$ vibrational modes (Figures 4 and 5), which are mainly related to the lipids and/or membrane phospholipids conformation [16].

Variations in the cellular properties of the samples, as reported here, may result from a number of cellular mechanisms which can manifest as a post-translational modification (chemical processes resulting in the cleavage or modification of proteins) such as glycosylation, phosphorylation or epigenetic changes (heritable changes not due to changes in the DNA sequence) e.g. histone modification, DNA methylation. The sensitivity of the analysis used in this study is unlikely to identify such specific changes in cells, but both post-translational modification and epigenetic changes have been observed utilizing surface-enhanced Raman spectroscopy [44-46] and variation between the cell types used are potentially the result of an accumulation of these cellular changes. Notably, however, more sophisticated multivariate classification techniques can be applied to achieve higher degrees of sensitivity and specificity for real clinical applications $[28,47,48]$. The results suggest, however, that the ethanol can initiate a disease process, due the interaction with and damage to the lipid structure present in the cell, which could further manifest as a neoplastic transformation and warrants further investigation. 
Maasland et al. have demonstrated that alcohol consumption of $\geq 30$ grams ( $\mathrm{g}$ ) per day (regardless of the source), compared with abstinence, was associated with a statistically significantly increased risk of HNC overall. These results are consistent with those of previous studies, showing alcohol consumption to be an independent risk factor for the development of HNC, with a strong, dose-response relationship [4-11,49-53]. Ethanol and acetaldehyde, the main metabolite of ethanol, are classified as a class I carcinogens and are considered to be the causative agents in drinking relating HNC. It is plausible that alcohol acts both directly and indirectly (through its metabolic byproducts) in HNC carcinogenesis, the latter for example by acting as a solvent for other possible carcinogens, such as the compounds found in tobacco products.

These findings indicate that ethanol itself probably is the most important factor in determining $\mathrm{HNC}$ risk, rather than other substances in alcoholic beverages (such as malt, corn, grape juice, etc.), which is consistent with the results from other studies [49,54-56]. Two potential explanations can be hypothesized, firstly, the membrane damage through ethanol exposure could initiate oral carcinogenesis directly, or secondly, the damage acts as a co-factor for other etiopathogenic substances, once the cell membrane is compromised, and the cells physical defense barrier is unable to protect the cell. Thus, the co-operative effect of alcohol consumption and cigarette smoking is biologically plausible, since alcohol can act as a solvent for carcinogens in cigarette smoke, along with permeabilizing the mucosa allowing easier access of these potential carcinogens. As a result, the carcinogenic properties of both factors are likely to be cumulative in the presence of one another. In conclusion, this study using Raman spectroscopy and dynamic molecular modelling showed that the ethanol could affect the cells mainly in lipid structure. In terms of oral mucosa, it could be related to a carcinogenic initiation or 
progression, in association with tobacco or alone, although more studies are needed to further elucidate this.

\section{DISCLOSURE/CONFLICT OF INTEREST}

None declared

\section{ACKNOWLEDGEMENTS}

Luis Felipe CS Carvalho was funded by Fundação de Amparo a Pesquisa do Estado de São Paulo - FAPESP for post doctoral research (2014/05978-1) and by the Conselho Nacional de Desenvolvimento Científico e Tecnológico (CNPq - Brazil) for post doctoral research under Science Without Borders (237749/2012-2) Laurita dos Santos was funded by Coordenação de Aperfeiçoamento de Pessoal de Nível Superior - CAPES for post doctoral research $(88881.062862 / 2014-01)$.

\section{REFERENCES}

[1] P. Boyle, B. Levin. World cancer report. International Agency for Research on Cancer, Lyon (2008).

[2] L.G. Cabral, L.F. de Carvalho, J. Salgado, et al. Gingival squamous cell carcinoma: a case report. J Oral Maxillofac. Res. (2010) 1-3.

[3] K. Kelly, S. Johnson-Obaseki, J. Lumingu, et al. Oncologic, functional and surgical outcomes of primary Transoral robotic surgery for early squamous cell cancer of the oropharynx: A systematic review. Oral Oncology. (2014) 50 8:696-703.

[4] D. H. Maasland, P. A. van den Brandt, B. Kremer, et al. Alcohol consumption, cigarette smoking and the risk of subtypes of head-neck cancer: Results from the Netherlands cohort study. BMC Cancer. (2014) 14. 
[5] H. Boeing, E. Working. Alcohol and risk of cancer of the upper gastrointestinal tract: First analysis of the EPIC data. IARC scientific publications. (2002) 156 151-4.

[6] M. Gronbak, U. Becker, D. Johansen, et al. Population based cohort study of the association between alcohol intake and cancer of the upper digestive tract. BMJ. (1998) $3177162844-848$.

[7] I. Kato, A. M. Y. Nomura, G. N. Stemmermann, et al. Prospective study of the association of alcohol with cancer of the upper aerodigestive tract and other sites. Cancer Causes Control. (1992) 3 2;145-151.

[8] K. Kjærheim, M. Gaard, A. Andersen. The role of alcohol, tobacco, and dietary factors in upper aerogastric tract cancers: a prospective study of 10,900 Norwegian men. Cancer Causes Control. (1998) 9(1):99-108.

[9] M. Hashibe, P. Brennan, X. Castellsague, et al. Interaction between tobacco and alcohol use and the risk of head and neck cancer: Pooled analysis in the international head and neck cancer Epidemiology consortium. Cancer Epid Bio Prev. (2009) 18 541-550.

[10] B. Y. Goldstein, S-C. Chang, M. Hashibe, et al. Alcohol consumption and cancers of the oral cavity and pharynx from 1988 to 2009: An update. Eur J Can Prev. (2010) 19 $431-465$.

[11] IARC: Monographs on the evaluation of carcinogenic risks to humans: Personal habits and indoor Combustions. International Agency for Research on Cancer; (2012).

[12] H. V. Ly, D. E. Block, M. L. Longo. Interfacial tension effect of ethanol on lipid Bilayer rigidity, stability, and area/molecule: A Micropipet aspiration approach. Langmuir. (2002) 18 8988-8995. 
[13] S. Y. Lee, H. J. Park, C. Best-Popescu, S. Jang, Y. K. Park. The effects of ethanol on the morphological and biochemical properties of individual human red blood cells. Plos One. (2015).

[14] Y. O. Posokhov, A. Kyrychenko. Effect of acetone accumulation on structure and dynamics of lipid membranes studied by molecular dynamics simulations. Comp Biol Chem. (2013) $4623-31$

[15] P. P. Babu, L. R. Kumari, M. C. Vemuri. Differential changes in cell morphology, macromolecular composition and membrane protein profiles of neurons and astrocytes in chronic ethanol treated rats. Mol Cel Biochem.(1994) 1301 29-40.

[16] L. F. Carvalho, É. T. Sato, J. D. Almeida, et al. Diagnosis of inflammatory lesions by high-wavenumber FT-Raman spectroscopy. Theor Chem Acc. (2011) 130 1221-1229. [17] S. C. G. Penteado, B. P. Fogazza, C da S. Carvalho, et al. Diagnosis of degenerative lesions of supraspinatus rotator cuff tendons by Fourier transform-raman spectroscopy. $J$ Bio Opt. (2008) 13 14-18

[18] C. Kallaway, L. M. Almond, H. Barr H, et al. Advances in the clinical application of Raman spectroscopy for cancer diagnostics. Photo PhotoTher. (2013) 10 207-219.

[19] H. Nawaz, F. Bonnier, A. D. Meade, et al. Comparison of subcellular responses for the evaluation and prediction of the chemotherapeutic response to cisplatin in lung adenocarcinoma using Raman spectroscopy. The Analyst. (2011) 1362450.

[20] L. F. de Carvalho, R. A. Bitar, E. A. L. Arisawa, et al. Spectral region optimization for Raman-Based optical biopsy of inflammatory lesions. Phot Las Surg. (2010) 28 111117

[21] D. Evers, B. Hendriks, G. Lucassen, et al.. Optical spectroscopy: Current advances and future applications in cancer diagnostics and therapy. Fut Oncol. (2012) 8 307-320. 
[22] J. M. Schubert, B. Bird, K. Papamarkakis, et al. Spectral cytopathology of cervical samples: Detecting cellular abnormalities in cytologically normal cells. Lab Invest. (2010) 90 1068-1077.

[23] S. Marur, A. A. Forastiere. Head and neck squamous cell carcinoma: Update on Epidemiology, diagnosis, and treatment. Mayo Clinic Proceedings. (2016) 91 386-396.

[24] L. Wang, Z. Zhang, L. Huang, et al. Evaluation of Raman spectroscopy for diagnosing EGFR mutation status in lung adenocarcinoma. The Analyst. (2014) 139 455463.

[25] K. Tanahashi, A. Natsume, F. Ohka, et al. Assessment of tumor cells in a mouse model of diffuse Infiltrative Glioma by Raman spectroscopy. BioMed Res Intern. (2014) 2014:1-8.

[26] M. Marro, C. Nieva, R. Sanz-Pamplona, et al. Molecular monitoring of epithelialto-mesenchymal transition in breast cancer cells by means of Raman spectroscopy. Bioch et Biophys Acta. (2014) 1843 1785-1795.

[27] N. P. Damayanti, Y. Fang, M. R. Parikh, et al. Differentiation of cancer cells in twodimensional and three-dimensional breast cancer models by Raman spectroscopy. J Bio Opt. (2013) 18117008

[28] F. M. Lyng, E. O. Faoláin, J. Conroy, et al. Vibrational spectroscopy for cervical cancer pathology, from biochemical analysis to diagnostic tool. Exp Mol Pathol. (2007) 82 121-129.

[29] S. Luo, C. Chen, H. Mao, et al. Discrimination of premalignant lesions and cancer tissues from normal gastric tissues using Raman spectroscopy. J Bio Opt. (2013) 18. 
[30] R. Mittal, M. Balu, T. Krasieva, et al. Evaluation of stimulated raman scattering microscopy for identifying squamous cell carcinoma in human skin. Las Surg Med. (2013) 496-502.

[31] S. P. Singh, A. Sahu, A. Deshmukh, et al. In vivo Raman spectroscopy of oral buccal mucosa: A study on malignancy associated changes (MAC)/cancer field effects (CFE). The Analyst. (2013) 138:4175.

[32] D. Naumann. FT-Infrared and FT-Raman spectroscopy in biomedical research. App Spec Rev. (2001) 36 239-298.

[33] D. Naumann, W. Chichester. Infrared spectroscopy in microbiology. Applications, Theory and Instrumentation. In: Meyers RA (ed) Encyclopedia of analytical chemistry. (2000).

[34] J. H. Nazemi, J. F. Brennan. Lipid concentrations in human coronary artery determined with high wavenumber Raman shifted light. J Bio Opt.. (2009) 143.

[35] R. Vyumvuhore, A. Tfayli, H. Duplan, et al. Effects of atmospheric relative humidity on stratum Corneum structure at the molecular level: Ex vivo Raman spectroscopy analysis. The Analyst. (2013) 138:4103.

[36] K. O'Callaghan, J. O’Sullivan. Ethanol Directly Modulates Reactive oxygen species generation in oral squamous cell carcinoma cell lines. Eur J Can. 2012;48:102.

[37] S. Pronk, S. Pall, R. Schulz, et al. GROMACS 4.5: A high-throughput and highly parallel open source molecular simulation toolkit. Bioinformatics. (2013) 29 845-854. [38] O. Berger, O. Edholm, F. Jähnig. Molecular dynamics simulations of a fluid bilayer of dipalmitoylphosphatidylcholine at full hydration, constant pressure, and constant temperature. Biophys J. (1997) 72 2002-2013. 
[39] H. J. C. Berendsen, J. P. M. Postma, W. F van Gunsteren, et al. Molecular dynamics with coupling to an external bath. J Chem Phys. (1984) 813684.

[40] G. Bussi, D. Donadio, M. Parrinello. Canonical sampling through 400 velocity rescaling. J Chem Phys. (2007) 126 014-101.

[41] W. J. Allen, J. A. Lemkul, D. R. Beva. GridMAT-MD: A grid-based membrane analysis tool for use with molecular dynamics. J Comp Chem. (2009) 30 1952-1958.

[42] L. M. Fullwood, D. Griffiths, K. Ashton, et al. Effect of substrate choice and tissue type on tissue preparation for spectral histopathology by Raman microspectroscopy. The Analyst. (2014) $139446-454$.

[43] F. Bonnier, S.M. Ali, P. Knief, H. Lambkin, K. Flynn, V. McDonagh, et al. Analysis of human skin tissue by Raman microspectroscopy: Dealing with the background. Vibrational Spectroscopy, (2012) 61 124-132.

[44] N. Sapay , W. F. D. Bennett, D. P Tieleman. Thermodynamics of flip-flop and desorption for a systematic series of phosphatidylcholine lipids. Soft Matter. (2009) 5 3295

[45] Z. Movasaghi, S. Rehman, I. U. Rehman. Raman spectroscopy of biological tissues. App Spec Rev. (2007) 42 493-541.

[46] A. Barhoumi, N. J. Halas. Detecting chemically modified DNA bases using surfaceenhanced Raman spectroscopy. J Phys Chem Let. (2011) 2 3118-3123.

[47] N. Sundararajan, D. Ma, S. Chan, et al. Ultrasensitive detection and characterization of Posttranslational modifications using surface-enhanced Raman spectroscopy. Anal Chem. (2006) 78 3543-3550.

[48] M. Lasalvia, P. D’Antonio, G. Perna, et al. Discrimination of different degrees of oral squamous cell carcinoma by means of Raman microspectroscopy and atomic force microscopy. Anal Methods (2015) 7 699-707. 
[49] C. Knipfer, J. Motz, W. Adler, et al. Raman difference spectroscopy: A non-invasive method for identification of oral squamous cell carcinoma. Bio Opt Exp. (2014) 5 32-52. [50] H. Haenel. Alcohol drinking. IARC monographs on the evaluation of carcinogenic risks to humans. (1989) 33 982-982.

[51] N. D. Freedman, A. Schatzkin, M. F. Leitzmann, et al. Alcohol and head and neck cancer risk in a prospective study. Brit J Can (2007) 1469-1474.

[52] M. Hashibe, P. Brennan, S. Benhamou, et al. Alcohol drinking in never users of tobacco, cigarette smoking in never drinkers, and the risk of head and neck cancer: Pooled analysis in the international head and neck cancer Epidemiology consortium. J Nat Can Inst. (2007) 99 777-789.

[53] C. Pelucchi, S. Gallus, W. Garavello. Alcohol and tobacco use, and cancer risk for upper aerodigestive tract and liver. Eur J Can Prev. (2008) 17 340-344.

[54] P-H. Chyou, A. M. Y. Nomura, G. N. Stemmermann. Diet, alcohol, smoking and cancer of the upper aerodigestive tract: A prospective study among Hawaii Japanese men. Int J Can. (1995) 60 616-621.

[55] World Cancer Research Fund: American Institute for Cancer Research: Food, Nutrition, Physical Activity and the Prevention of Cancer: a Global Perspective. Washington DC: American Institute for Cancer Research (2007).

[56] M. P. Purdue, M. Hashibe, J. Berthiller, et al. Type of alcoholic beverage and risk of head and neck cancer--a pooled analysis within the INHANCE consortium. A J Epid. (2008) 169 132-142. 


\section{FIGURE LEGENDS}

Figure 1: Image displaying the interaction between the cell membrane and $1 \%$ ethanol prepared using molecular dynamics: a) 0 ns of simulation and b) after end of simulation (100ns). c) Density profile (arbitrary units) of the molecules in the system at initiation (dash line) and termination (solid line) of the simulation.

Figure 2: Image capture of the initiation of the simulation at 0 ns (a) and its matrix thickness (b). The matrix is calculated based on the distance between two phosphorus (P) atoms of the two DPPC molecules aligned in different monolayers.

Figure 3: Image capture of the termination of the simulation at $100 \mathrm{~ns}$ and its matrix thickness. In this distance matrix the red color (largest distance between two $\mathrm{P}$ atoms) is predominant compared with Figure 2.

Figure 4: Averaged high wavenumber Raman spectra of all cell lines before (red) and after (black) $1 \%$ ethanol treatment. Mann-Whitney test of the lipid vibrational modes shows that changes in the region are statistically significant, $p<0.001$, demonstrating 
excellent discrimination of these types of samples in the region related to the vibrational modes of lipids $/ \mathrm{CH}_{3}$.

Figure 5: Relationship between the intensity of the $2851 \mathrm{~cm}^{-1}$ peak for each cell line in the presence and absence of ethanol, ${ }^{* *} \mathrm{p}<0.001$ and $* \mathrm{p}<0.05$ 